\title{
Winning the Economic War The Business of Science
}

\author{
Hazel R. O'Leary
}

The following is an edited transcription of the plenary address given by U.S. Department of Energy Secretary Hazel R. O'Leary at the 1993 MRS Fall Meeting.

Tonight, I'm not going to talk about the Department of Energy's role in support of materials research because there is a bigger issue that we need to be talking about-the role science and technology can and must play in driving the U.S. economy. We ought to be focusing on the real business of science, and, like it or not, science is a business.

In the Clinton administration we are focusing on using science and technology as a strategic weapon and on what I'm calling the new war, the economy war.

Why would the administration and I be saying that? If you recall, the theme of the campaign waged by Bill Clinton was the economy. Then early on, when he took leadership, he staged an economic summit, and immediately joined in a partnership with Al Gore to begin focusing on science and technology and articulating clearly the goals that he saw for driving the economy. People quite clearly didn't focus on the Department of Energy during that early dialogue. Most people had no idea that the national laboratories exist, that there is a strong nexus between the labs and the research community and, perhaps most importantly, that there is great work going on in materials research, much of it supported through the Department of Energy's budget.

We've learned as business people that we really don't want to focus on the budget alone and that the Department has a great sum of money to invest in this area. The real issue is what happens with that budget.

Now, in the old days, the United States was a major player in terms of economic competitiveness. Until around the early 1980 s, there was no question that the United States was dominant in science and technology and certainly in economic prowess. Much of that prowess came out of focusing on materials, and a great deal of it resulted from the Department of Energy's focus on national security.

We focused on shaping what the nation wanted to address in science and technology, at that time, national security, by asking what it takes to keep America safe from the threat, first of all, of communism and then, certainly, of the nuclear bomb.

Interestingly enough, some people understood and talked about dual technology then. They've been talking a great deal about it lately, and my friends who are scientists and technologists can clearly point to the fact that national defense was then the primary focus, and that science was a sometimes almost secret study and production that took place behind very high walls.

Today, that's not the case. Some, but certainly not all in this crowd, would say that the United States hasn't lost the economic war. Nevertheless, we're surely

\section{If you can't tie the work we're all doing to increasing the GDP, that work is not likely to gain the support it needs.}

not head and shoulders above Western Europe and Japan the way we were in the early 1980 s.

Let's talk about what science and technology have done, either working toward public goals or standing alone for its own sake. I will posit that science has never worked in complete isolation-it has always driven something. But what has it

Material Matters is a forum for expressing personal points of view on issues of interest to the materials community. accomplished in the United States? Well, most people believe that over the past two or three decades, some 25 to $50 \%$ of the economic growth in this country can be attributed to science and technology. That's a big piece of the pie, and one that most people don't talk about.

Certainly, everyone in the room will agree that it was the science and technology, along with some fine diplomacy and maybe a lot of good luck, that secured the peace for us because without real dominance in national security and our weapons capability, there would have been no peace. Or, some would argue, it might have come more slowly. But what we had built on the back of science and technology took us there.

Surely, we would all admit that it has enhanced the quality of life here in the United States and internationally. Research is conducted, and such research has contributed, for example, to the development of cancer treatments and the treatment and identification of birth defects....My point is, it's all come to us through science and technology.

I want to focus just a bit on securing the peace. How do we do that? With a huge push on technology. I've become a student of the old Atomic Energy Commission and ERDA (Energy Research and Development Administration). Most of you know how we got things done. No one ever argued about the budget. No one ever did to their projects what recently was done to the Super Collider. Even the Space Station had to ask, "can we afford it?" Formerly, it was simply a "must do" thing because our national priority was securing the defense. Every mind and all efforts were behind it, and there was never any debate over whether that was right or wrong.

Much of the decision-making regarding the budgets, resources, and methodology for defense projects occurred without any national debate. It was all simply a given, it was understood, and not even the goals set for the program were articulated.

Why? Well, as I've said, the program was defense driven and seemed to be important. It was also classified, giving us some of the problems we've inherited today....And it was pretty much thought of as a Lone Ranger activity.

What do I mean by that? I'm not talking about physicists who demand their own laboratories and their own microscopes or "this is my stuff that I don't want to share with anybody else." What I mean is not collaborating with the private sector and certainly not with the government. It was more like, "This is the man- 
date, this is the mission. It's going to be secret, so we're going to go off by ourselves and accomplish it."

What effect did that have? It established a community of people who pretty much moved back and forth within their own disciplines and had little interconnection with others. Now, some of us would posit that at that time and under those circumstances, such behavior was appropriate. I'll show you later that perhaps it is not totally appropriate today.

\section{Winning the "New War"}

Now, to enlist your aid in winning what we're calling the new war, we first of all have to convince you that there is a new war. How do we do that? I don't know. What comes to mind is that when I'm in Florida talking to a group of people about NAFTA (North American Free Trade Agreement)--trying to get support in the United States because I think NAFTA's the juice that's going to jumpstart our technology in this hemisphere, then push it into international market-
places-I get a Brit in the room who stands up and says to me, "Well, we hope you don't pass NAFTA, Ms. O'Leary, because, quite frankly, we'd like your market, and we'll compete with you anyway, but it will be much easier for us to compete with you if there is no NAFTA."

What have we understood clearly in this administration? We have understood that economic expansion is going to come from global markets, from growing these markets, and that it's energy, technology, and science that are going to drive our gross domestic product.

If from no other reason than watching the Superconducting Super Collider cave in like a wall of bricks, I know that if you can't tie the work we're all doing to increasing the gross domestic product, that work is not likely to gain the support it needs. So we'd better be making a contribution, which is tough for us because we're accustomed to doing our work pretty much alone and to not having to defend it.

And, as if that weren't enough, there's more. I just referred to us as Lone
Rangers. But believe me when I say that if we're going to win the new war for economic dominance, we must relinquish our Lone Ranger status and become partners with the private sector. By private sector, I don't mean the laboratory scientists in our companies, but the people who understand the marketplace and consumer demands. We must seek such partnerships so that the products we're focusing on developing are going to be the ones promoted to consumers.

Recently, I was at Motorola talking to some of their executives and I heard some wonderful comments about consumer research. They wanted to find out how consumers felt about those wonderful pagers we all wear now, so they surveyed a group of nine-year-olds who were visiting their museum. According to those youngsters, the world really wanted the pagers, and in colors very much like the suit I'm wearing, and in green, yellow, and blue, or in gray or brown. Why? So they could be color-coordinated.

The whole idea was to have a group of youngsters provide the input. Now, most of us who live in our ivory towers might have said, "Colors aren't such a good idea." But when Motorola went out and did some focus groups, guess what the real customers told them? "Yes. We want pagers in hot pink and blue and green." That's one way to expand the market. Is that important? You bet it is, because Motorola has to keep rolling up the work.

Another piece of the puzzle is cost effectiveness. The only reason the private sector is even dealing with us as a governmental entity or in our national labs, or perhaps with you too, is because profit margins are down a bit. So the only way we get to do the real research that's required is to partner with someone.

Say, as a business, I'm partnering with the government. Guess what I want? I want the best price. I want value-added or the research is no good to me. That's a real challenge for us because we've not had to do that.

Finally, the last requirement may be the hardest, and it is that the work be timely. What does timely mean? Well, I come from a utility background and in that setting timely can sometimes mean 20 years. But timely to most people who are now dealing with the government, and requesting delivery of what I call strategic research and technology or science, is six months to two years, because that's the cycle in which they want to bring products to market.

Now, this creates a problem because we still think we ought to be doing some 
basic research without some early benefit that we can foresee, and the challenge is to keep the balance between the shorter and longer term goals. But today I want to talk about how we secure markets in the short term, and I'll come back to that .

I've outlined the requirements and also alluded to the fact that they may just be a bit difficult for the 20-odd national labs that loosely-and I do mean looselydeal with the Department of Energy. Sometimes we'd like to use the term

\section{The only way we get to} do the real research that's

\section{required is to partner with someone.}

"report to," but we all know that's inaccurate. We can, however, talk about a partnership, because I think one exists, and we are recognizing now that we need each other desperately, and that's the core of my pitch to the labs.

\section{What Needs to Be Fixed?}

If the Department of Energy is to gain and maintain expertise in materials management and in other areas it dominates through its laboratories, a number of things need to be fixed. First, we need to enhance public understanding of what goes on at our national laboratories, something most people don't understand.

Sometime after I accepted this position, I said to someone, "I'm going to be head of the Department of Energy," and they said, "Oh, you're going to do some energy policy." And I said, "No. I've got 27 national laboratories that I have to try to keep focused on doing some meaningful work." But perhaps more significantly, most of the people who know anything about the national laboratories say, "Oh, yeah. We know those guys. They do defense work. They build bombs."

People are not aware that great work is coming out of the labs, in materials management, research, energy efficiency, and alternative energy. Great work in science, great work in medicine, work that people don't know about. The popular view is that researchers in national labs work pri- marily in defense and are, therefore, not needed anymore. Moreover, they reason, since everyone else is looking for additional money or trying to cut the deficit, the labs' budgets could be spent more wisely elsewhere.

When I hear comments like that, I say, "No. Wait a minute. There are great capabilities in our national labs that go far beyond the building of bombs." To you I say-and I choose the verb carefully"Blast the public perception of the national laboratories so that people both understand what happens there and appreciate the benefits that accrue to the public from those laboratories."

Someone in my administration remarked that the national labs are a relic of the past. That's bad because these labs are sites of competence and excellence. All of us in this room know that the national labs are the places where some 15 Nobel Prize Laureates have worked and through which they've made their contributions; they're the places where many of you go on a day-to-day basis to do some of your work and research. The public has no idea that this happens nor does it

\section{UNMATCHED PRECISION. QUALITY SEMICONDUCTOR MATERIALS PROCESSING SINCE 1967.

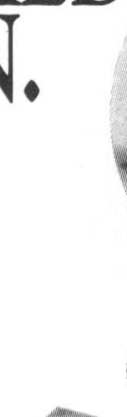

\section{SEMICONDUCTOR PROCESSING COMPANY}

409 East First St., Boston, MA 0212 617/269-4422 FAX: 617/269-4659

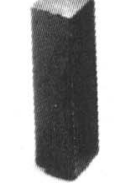

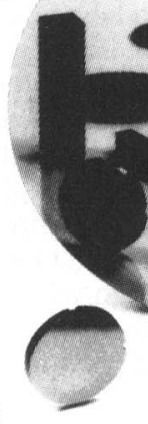
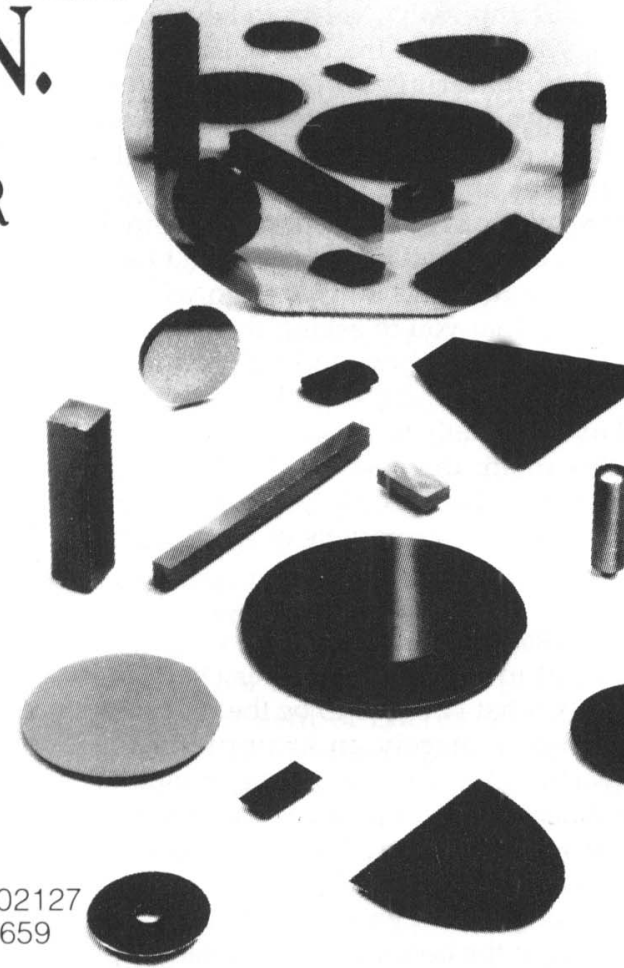

Circle No. 28 on Reader Service Card.
ADVANCED TECHNOLOGY.

Simultaneous two-sided polishing for high preci-

sion micromachining

applications. $25 \mathrm{~mm}$

through $125 \mathrm{~mm}$ silicon

wafers with <2um thick-

ness variation!

SPECIAL MATERIALS. Silicon, germanium and a variety of III-V compound semiconductors.

CUSTOM SERVICES. COMplete wafer fabrication. Slicing, grinding, lapping, polishing and dicing.

FLEXIBILITY. Virtually any orientation, shape, size or thickness. Research or production quantities in 4 weeks or less.

QUALITY CONTROL. Quality and calibration systems conform to MIL-|-45208A and MIL-I-45662. 
know of the tremendous national investment in the infrastructure for the national labs, where that work gets done. We need to do something about that.

Finally, the big thing that needs to be done-and this gets back to the debacle of the Super Collider and some of the work that's been taken away from the space station and NASA-is to create some public consensus on what national investment we need to make in science and technology, not necessarily for the near term, for the early strategic science and technology, but for basic science. We need some agreement from the public generally that there's a need for such investment and a need to explore the boundaries of science and technology without clearly understanding what the benefits are today or might be for the short term.

I would contend that no one has done the work of attempting to shape such a consensus for the public, and I'd like to get back to why. One factor is the Lone Ranger mystique, the sense that scientists and public policy people generally work totally apart from one another. There's also a sense that now that the nation can afford an investment in science and technology, nobody's carrying the ball. People may think about this issue in passing, but they're not discussing it in broad public fora. That's the bad news.

\section{What's in the Arsenal?}

What's the good news? There are strengths. Someone has called the national laboratories the nation's crown jewels. I think that's true, not just for the defense labs, but also relative to the capabilities within the multipurpose labs. Seats of excellence exist in those labs and we need to tout that. Many of the laboratories have enhanced the public's understanding of their activities simply by opening the door and inviting the public in, even when we've had classified work going on. For the first time, foreign scientists have been brought in and, for the first time, reports have been issued so that the public can understand the accomplishments and the tradition of excellence in our national labs and come to think of it as an everyday matter, not as something special or secret.

A world-class technology base that has existed for years stands ready to be built on, but, once again, people don't know about it. So, anything that can be done by you in your work, by the national laboratories, or by the universities to increase public understanding of science and technology is good.

\section{The excellence of materials research is widely known and can be a springboard for building awareness.}

Also, we've got to do something with the people who now set public policy. Again, I go back to the loss of the Collider and some 140 people who didn't so much focus on budget overrun as on the relevance of the project. It was simply, "I don't understand what that does." In considering the loss of that vote, another factor becomes apparent. You can't show up 90 days before a vote is going to be taken, or even once a year, to say, "Hi. I'm a world-class scientist. I've come here to talk to you about my project." It will not do. Everyone else who's in there pitching a public policy piece or, perhaps more importantly a piece of the budget, is showing up almost every day. So we need to get the word out, and not just at cocktail parties or lunches, but through building relationships with staffers, both in the committees that have responsibility for science and technology and broadly throughout the Congress.

I'm doing some of that, but I'm not nearly as impressive as would be a whole lot of you going in frequently. The excellence of materials research is widely known and can be a springboard for building awareness. How? By making the rounds, by showing people the products that result from good science and technology, by explaining why we couldn't have had these products 10 years ago without the work that you're asking them to support, by doing "show and tell" for folks, so they understand the work you do.

Finally, what's in the arsenal is what's in this room: the best and the brightest. Who better than people like you to teach others about the marvels of science and technology.

\section{Our Strategy}

I want to show you, via this chart (see Figure), what I believe to be the dilemma. And this is merely an example of the Department of Energy taking a look at the defense budget as we know it today. What we've attempted to do is point out how some of the DOE's budget for research and development is spent. Looking at the bottom section, which represents fiscal year 1994, you can see that today the biggest portion of the budget goes toward our defense program.

Another portion--and it's very tiny, $\$ 250$ million-is what we call our industrial competitiveness piece. This portion comprises the things we believe we are doing well to drive applied science and technology and actually move jobs into the private sector. It's very small. Every agency in government now doing work in science and technology wants to take its meager budget from this end, to grow it from here because the national security portion of the chart is decreasing now. No matter what we use as a proxy for bomb testing, that budget is going down.

Why should you care? Let me explain. The basic science budget of the Department, and this is not the whole piece of the pie, is represented in energy efficiency and renewables. Now, I can blow this up and get the $\$ 6$ billion, but you understand the snapshot I've taken simply from the national defense laboratory perspective.

We've got great laboratories and great scientists, but I'm not sure I've got the money over the long haul to take us into the 21 st century, to keep everyone excited and motivated. Now, some in the Congress would say, "So what's the big deal? Let's close a few labs." One of my colleagues said to me, "Well, what does it matter that you've closed a few labs?" What matters is that we lose the capability as a nation to think, to shape, and to move the U.S economy. We also lose the ability to excite others and to create a legacy for the future.

Here's our plan. First, we want to grow the portion called industrial competitiveness, and that means, quite frankly, to put more of our scientific muscle toward earlier delivery of the product to the marketplace. The private sector wants and needs our products. Moreover, this scenario matches the industrial policy of every nation in the world that's about to beat our socks off.

Forget that Japan is more or less on the ropes now, along with all of western Europe. Understand that each of the nations that has given us a run for our money has done it by recognizing, first of all, that industrial competitiveness ties well with science and technology, and that their government has mandated support in areas they thought would make these countries more competitive. Let's decide that there's great and excellent work to be done here. That decision keeps the resource called the national laboratory enriched and working.

Finally, let's look at the basic science portion, not just things like the Super- 


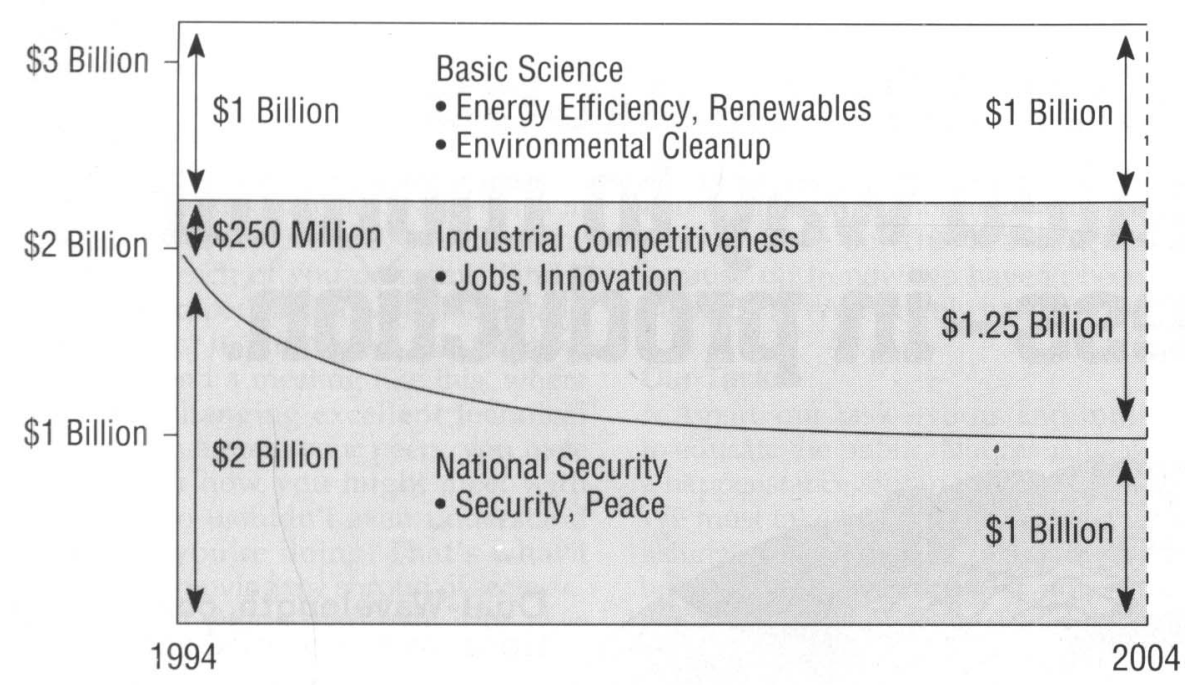

The Department of Energy's new investment strategy, 1994 to 2004.

conducting Super Collider, but energy efficiency work, much of the work to be done in renewables, and, of course, cleanup from the production of nuclear weapons over the past 40 years. We'll take the top of that line and hold it where it is today, permitting us to do some great research over the long haul without being focused on deliverables for the short term.

This ought to be the new investment strategy. Now, where I have a problem with this, and so does the rest of the world, is, where exactly does one draw the line between the applied science portion and the basic science portion? I want to discuss it in terms of "fundamental" and "strategic," the strategic portion being the one that drives the economy. That's the dilemma. That's the public debate that needs to be held, and I think that you are the right folks to help get that public debate started.

\section{Three Partnership Success Stories}

I'd like to talk about some models on the applied side that I think have worked very well, although you might disagree with me. The first one is brand new, so no one is in a position to judge it. That's the clean car initiative. This initiative, in my mind, represents for our administration the first piece of what I'm going to call pseudo industrial policy.

I didn't stand up and say, "Hey, this administration now has a solid policy for using science and technology to drive the economy by helping selected industries," but, in fact, we did focus on the auto industry. Why? Because the public policy need and that of the industrial sector are well-matched.

With respect to the economy, if the auto industry doesn't once again become strong against its international competitors, then we've got a problem because jobs depend on it. But perhaps the real force behind our decision is that the automotive sector needs to be improved if we're going to improve the environment, meet some of our goals for global climate change and, of course, meet some of our goals for ensuring great jobs for Americans, that is, high-wage, high-paying, skilled technical jobs.

That was an easy task, for what we did without shocking anyone was simply to reprogram commitments in the federal budget to set aside $\$ 1$ billion that we're now willing to put on the table and cost share with the Big Three auto industries, if they will put their $\$ 1$ billion on the table. The goal is the car of the 21st century, whose energy efficiency is improved by $300 \%$. We're also shooting for 80 miles a gallon, a tough goal because I don't think the industry believes we'll do the job. It would mean coordinating all the government's capabilities, science and technology together, and that hasn't often worked well.

Next, I want to talk about Amtex, which is not well known. For this project, the Department of Energy and the Department of Commerce committed about a half-billion dollars to help the fully integrated textile industry. The goal was to stop the loss of textile jobs to competitors abroad and to do it in areas where the laboratories, both Commerce and the Department of Energy, are knowledgeable, prepared, and able to make a differ- ence. Three areas were targeted for improvement. First, waste management and what I used to call energy conservation. Second, super computing: How to get the right data about customers to the suppliers who need it. That's a simple task with a small set of businesses flung throughout the United States. Third, materials management. Perhaps most important to the textile industry, which already has great productivity, is how to create a better product because that's the only way it can beat out cheaper labor. The goal is to create better textiles to satisfy customer demand for better clothing so that somebody like me, who is one size on the bottom and another size on the top, can order not off the rack, but through a book and get a suit three days later. That's the way to sell textiles.

My point is that the federal government is dealing with a fully integrated textile industry-another piece of what I call pseudo industrial policy-that is, the entire industry, from the growers of the cotton to the retail folks who bring textiles to the market. So there's no question about whether the Department of Energy or Commerce, through its laboratories, is picking the winner, that is, going with one company. Rather, we went with a whole industry because we thought it was important, again, for jobs.

The Sematech project is perhaps the most demonstrative of success. My administration doesn't own it, but I like to tout it because it's a good model for similar projects. The companies now represented by Sematech, clearly the international leaders, woke up one day and found themselves bested both in terms of their technology and their intellectual product being replicated outside of the United States, and getting their socks beaten off.

The Sematech people came to the government and to the national laboratories and said, "We're working together, and we will put our money on the table if the government will work with us in science and technology to help us gain back market share." About two months ago, finally, The Wall Street Journal declared victory for Sematech, and I think that's an example of the kind of government/ industry partnership we need, an example of how our industrial policy ought to be conducted.

Another model project is the advanced battery consortium, in which the government is working with a major auto industry and other battery manufacturers to come up with a smaller, more efficient one that runs for more than 20 miles without having to be hooked up at home. 
That's another example of what these partnerships can accomplish.

\section{Our Challenge}

Our challenge is to remove the shroud of secrecy from our work. Note that I'm not talking about the labs, but about the work that each of you performs. Find a way to help people know it, understand it, and honor it. That means that whenever you attend a meeting like this, where you're exchanging excellent technical information among your peers, you have to consider how you might meet with people who wouldn't even understand the work you're doing. That's what I mean by removing the shroud of secrecy.

How will we do that? Will it be user friendly? Again, that's a matter of language, not of style. I'm not suggesting that anybody change his or her style, but simply that we learn to be open and to invite people to understand what we're doing. And it's a great mission, as each of you know, because you will be celebrated for what you deliver to society.

Finally, and perhaps most importantly for those of us who aren't accustomed to it, is the challenge to communicate, again and again, the economic benefits of the work that we do. This is a difficult task because up to now we haven't been trying to do it. We've rarely had to do it.

\section{Our Task}

Again, our task-yours and mine-is to educate the public. Not casually, not as a happenstance, but in a planned fashion. We must take this on as a mission, establishing goals to indicate whether we have been successful enough or not, setting goals for educating the public about what we do and what its benefits are.

The other part of our task is easier, and it probably applies more to the labs and to most of you in the room. We need to get out of our cubbyholes. That relates to what I talked about in terms of our rela- tionship with the Congress and, even more importantly, with opinion-shapers and leaders. It means that each of us in this room needs to move out of his or her cubbyhole to the broader constituency to carry this message.

Finally, we have to create opportunities for public debate on these issues, and that's the assignment I'd like to leave with you. As Secretary of Energy, I think it's my job to accept invitations to meetings like yours because neither the Department of Energy nor the Nobel Prize Laureates who make occasional visits can do this alone.

The work of promoting the advantages of science and technology for moving us into the 21st century belongs to each one of us and it should go on in almost every forum. If you take away anything from this meeting, it should be to reflect on how your organization might help. That's what I need from each and every one of you. Thank you.

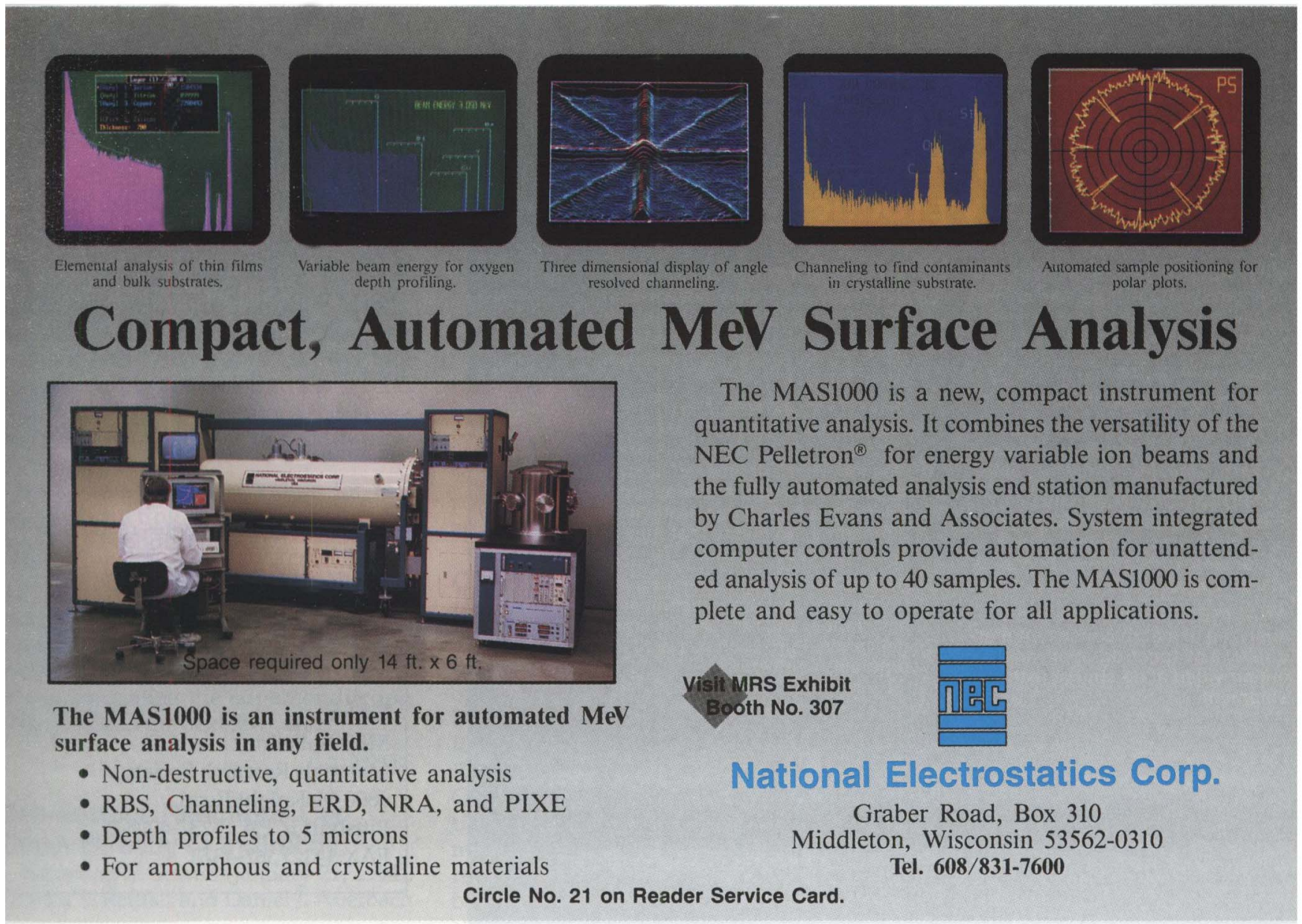

